\title{
Tension pneumothorax in a newborn after Cesarean- section delivery -A case report-
}

\author{
Sang Kwon Kim, and Won Ho Kim \\ Department of Anesthesiology and Pain Medicine, Seoul Medical Center, Seoul, Korea
}

Tension pneumothorax in newborns is a rare but life-threatening complication. We encountered a case of a full-term neonate with a breech presentation. An elective cesarean section was scheduled. Immediately after delivery, the newborn was found to be breathless with a heart rate $<60 / \mathrm{min}$. During intubation and cardiac massage, the patient's femoral artery and vein were accessed. The infantogram revealed a right side tension pneumothorax. A 22 gauge needle thoracentesis relieved the right side chest pressure and a closed thoracostomy was performed. The severe acidosis was corrected with sodium bicarbonate. The patient was managed in the neonatal intensive care unit, but died from uncorrectable acidosis. We report this case with a review of the relevant literature. (Korean J Anesthesiol 2010; 59: 420-424)

Key Words: Needle thoracentesis, Neonatal tension pneumothorax, Resuscitation of newborn, Tube thoracostomy.

Ten million or more newborns worldwide each year require some form of resuscitation assistance. More than 1 million babies die annually from complications of birth asphyxia [1]. The anesthesiologist may help resuscitate the newborn after unexpected arrest in the delivery room or during the cesarean section until the arrival of pediatricians, even though the pediatrics take charge of the newborn primarily. There are few reports of neonatal tension pneumothorax and its resuscitation. Recently, we encountered a case of neonatal cardiopulmonary collapse due to tension pneumothorax and its resuscitation. We report this case with a review of the relevant literature.

\section{Case Report}

A 38-year-old, $159 \mathrm{~cm}, 68 \mathrm{~kg}$ woman with a full-term pregnancy was admitted for a cesarean section due to a breech presentation of the fetus. She had previously undergone surgery to remove a benign ovarian mass two years earlier and two cases of abortion including one missed abortion. She was hospitalized for a threatened abortion at six months gestation, which caused no complications. Her blood pressure was 120/70 mmHg and the blood test results were within the normal limits. There were no specific findings in the physical examination.

Received: February 1, 2010. Revised: 1st, February 16, 2010; 2nd, March 11, 2010. Accepted: March 31, 2010.

Corresponding author: Won Ho Kim, M.D., Department of Anesthesiology and Pain Medicine, Seoul Medical Center, Samseong 1-dong, Gangnam-gu, Seoul 135-740, Korea. Tel: 82-2-3430-0201, Fax: 82-2-3430-0517, E-mail: bullet57@naver.com

This case has been presented at the Annual Meeting of the American Society of Anesthesiologist, Oct. 2010, San Diego, U.S.A.

(c) This is an open-access article distributed under the terms of the Creative Commons Attribution Non-Commercial License (http:// creativecommons.org/licenses/by-nc/3.0/), which permits unrestricted non-commercial use, distribution, and reproduction in any medium, provided the original work is properly cited. 
The fetus had reached full term after 38 weeks and one day of gestation. The fetal heart rate was approximately $140 / \mathrm{min}$ and there were no signs of fetal distress. For the induction of general anesthesia for a cesarean section, which was requested by the patient, pentothal sodium $5 \mathrm{mg} / \mathrm{kg}$ and succinylcholine $1 \mathrm{mg} / \mathrm{kg}$ were injected. After exposing the uterus using a Pfannensteil's skin incision, a female newborn was delivered with a fundal pressure. The induction-delivery time was 11 minutes, and the uterine incision-delivery time was 4 minutes.

The newborn showed no definite anomalous appearance but was flaccid without muscle tone or self-respiration. The 1 minute Apgar score was 2. Emergency resuscitation was initiated, while giving $100 \%$ free flow $\mathrm{O}_{2}$. After removing the foreign material in the oropharynx by suctioning, a $3.0 \mathrm{~mm}$ uncuffed endotracheal tube was intubated by the anesthesiologist using a Miller \#0 blade and fixed at $10 \mathrm{~cm}$. Immediately after intubation, a breathing sound was ascultated bilaterally and normally. Approximately 4 minutes had occurred from birth to intubation. The laryngoscope view revealed no meconium staining or any findings suggesting aspiration. The neonatal heart rate was $<60$ beats/min on the electrocardiogram and the $\mathrm{SpO}_{2}$ was $<60 \%$. Accordingly, cardiac massage was initiated along with $100 \% \mathrm{O}_{2}$. The pediatrician arrived at the operating room, and the remaining resuscitation was performed by cooperation between the anesthesiologist and pediatrician.

Amniotic fluid $5 \mathrm{ml}$ was drained via a G-tube. After 1 : 10,000 epinephrine $0.3 \mathrm{ml}$ was administered three times via

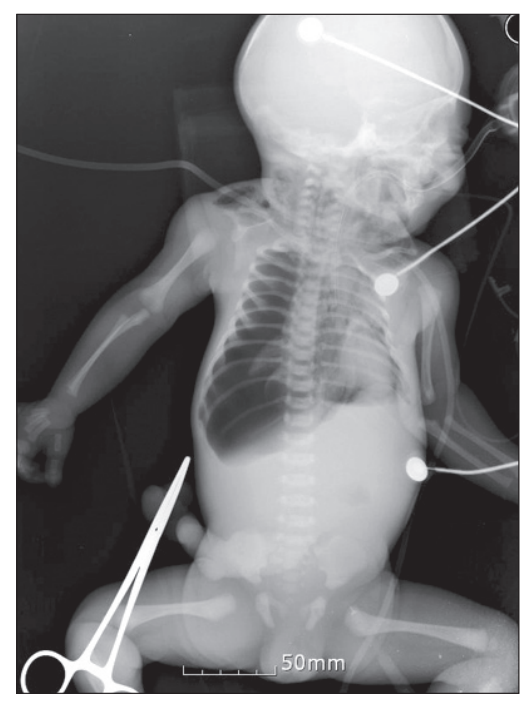

Fig. 1. The portable infantogram reveals a right side tension pneumothorax. Massive air collection is observed in the right lung field, which caused right lung to collapse completely. The mediastinal structures are shifted to the left side and a linear low density exists in the mediastinum, which is considered to be pneumomediastinum. Subcutaneous emphysema on the supraclavicular area can be seen on both sides. an endotracheal tube, the heart rate was increased to more than 100 beats/min, but the $\mathrm{SpO}_{2}$ remained at $60 \%$. Repeated auscultation revealed a right-sided decrease in breathing sound. Consequently, a portable infantogram was requested to evaluate the cause. To allow intravenous access, a 4 French 2 lumen central line catheter was inserted at the right femoral vein. Through a C-line, $1: 10,000$ epinephrine $0.3 \mathrm{ml}$ and 0.1 $\mathrm{mg}$ atropine were injected twice respectively. The infusion of dopamine $10 \mu \mathrm{g} / \mathrm{kg} / \mathrm{min}$ and epinephrine $0.05 \mu \mathrm{g} / \mathrm{kg} / \mathrm{min}$ were started simultaneously.

The infantogram revealed massive air collection in the right lung field and a mediastinal shift to the left side, which is considered to be a tension pneumothorax (Fig. 1). It took 30 minutes to diagnose the tension pneumothorax. Needle thoracostomy was performed in the right second intercostal space on the midclavicular line with a 22 guage intravenous cannula and decompression with $10 \mathrm{ml}$ syringe was started. The blood pressure after several decompressions was 80/60 mmHg, and the heart rate was 130 beats $/ \mathrm{min}$.

The first arterial blood gas analysis (ABGA) after 35 minutes from birth revealed a $\mathrm{pH}, \mathrm{PaCO}_{2}, \mathrm{PaO}_{2}, \mathrm{HCO}_{3}{ }^{-}$, bicarbonate (BE) and blood glucose of 6.665, $151.2 \mathrm{mmHg}, 24.1 \mathrm{mmHg}$, $16.9 \mathrm{mmol} / \mathrm{L}$ and $-22.4 \mathrm{mmol} / \mathrm{L}$, and $87 \mathrm{mg} / \mathrm{dl}$ at $\mathrm{FiO}_{2} 1.0$, respectively. Table 1 lists the other results including the cord blood ABGA. While assisting ventilation with AMBU bagging, $6 \mathrm{mEq}$ of sodium BE was administered slowly over a 3 minute period to compensate for the severe combined respiratory and metabolic acidosis. Chest tube insertion was performed by a thoracic surgeon using a 4 French 2 lumen central line catheter, and the time between birth to chest tube insertion was 45 minutes.

The $\mathrm{SpO}_{2}$ was increased to more than $95 \%$ after chest tube insertion, and rechecked infantogram showed an improved pneumothorax (Fig. 2). The ABGA checked 30 minutes after tube insertion was $\mathrm{pH}, \mathrm{PaCO}_{2}, \mathrm{PaO}_{2}, \mathrm{HCO}_{3}{ }^{-}$, $\mathrm{BE}$ and blood glucose of 6.891, $51.8 \mathrm{mmHg}, 234.8 \mathrm{mmHg}, 9.7 \mathrm{mmol} / \mathrm{L},-23.7$

Table 1. Arterial Blood Gas Analysis during Resuscitation

\begin{tabular}{lcccc}
\hline \multicolumn{1}{c}{ ABGA } & 35 min* & 55 min* & 75 min* & Cord blood \\
\hline $\mathrm{pH}$ & 6.665 & 6.725 & 6.891 & 7.195 \\
$\mathrm{PaCO}_{2}(\mathrm{mmHg})$ & 151.2 & 101.3 & 51.8 & 65.0 \\
$\mathrm{PaO}_{2}(\mathrm{mmHg})$ & 24.1 & 120.2 & 234.8 & 24.7 \\
$\mathrm{HCO}_{3}{ }^{-}(\mathrm{mmol} / \mathrm{L})$ & 16.9 & 12.5 & 9.7 & 24.6 \\
$\mathrm{BE}(\mathrm{mmol} / \mathrm{L})$ & -22.4 & -22.7 & -23.7 & -4.9 \\
$\left.\mathrm{Glucose}^{+} \mathrm{mg} / \mathrm{dl}\right)$ & 87 & 102 & 147 & - \\
$\mathrm{Na}^{+}(\mathrm{mmol} / \mathrm{L})$ & 143.5 & 139.4 & 142.2 & 145 \\
$\mathrm{~K}^{+}(\mathrm{mmol} / \mathrm{L})$ & 4.33 & 4.17 & 3.91 & 5.8 \\
$\mathrm{Ca}^{2+}(\mathrm{mmol} / \mathrm{L})$ & 1.14 & 1.34 & 1.21 & - \\
$\mathrm{Cl}^{-}(\mathrm{mmol} / \mathrm{L})$ & 119 & 113 & 116 & 118 \\
$\mathrm{Hb}^{(\mathrm{g} / \mathrm{dl})}$ & 17.0 & 17.0 & 15.3 & - \\
\hline
\end{tabular}

ABGA: arterial blood gas analysis. *Time after birth. 
$\mathrm{mmol} / \mathrm{L}$ and $147 \mathrm{mg} / \mathrm{dl}$ at $\mathrm{FiO}_{2}$ 1.0, respectively, which showed improved ventilation and oxygenation. However, the acidosis was still severe. Therefore, $6 \mathrm{mEq}$ of sodium BE was administered repeatedly. The blood pressure and heart rate was 70/50 $\mathrm{mmHg}$ and $>130$ beats/min, respectively, which were not stable (Table 2). Atropine $0.1 \mathrm{mg}$ and $1: 10,000$ epinephrine $0.3 \mathrm{ml}$ were also administered. The newborn was transferred to another hospital with AMBU bagging, as requested by the guardian.

The patient was managed in the intensive care unit, but died from uncorrectable acidosis and shock on the 2nd day of transfer. The mother recovered without complications. Focal pneumonia and small effusion was observed in chest PA at the second day after surgery. She recovered with antibiotics and conservative management, and was discharged on the 7 th day after surgery.

\section{Discussion}

The incidence of neonatal tension pneumothorax is unknown

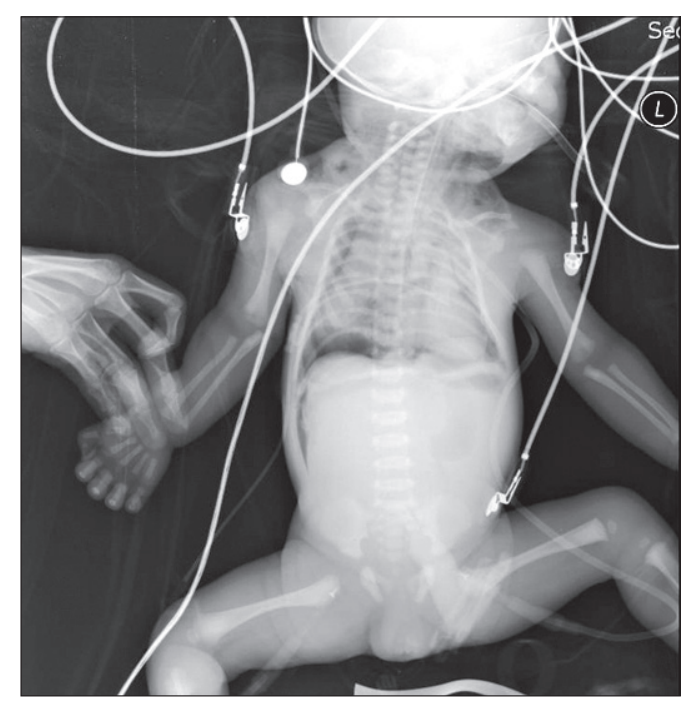

Fig. 2. Follow-up infantogram after insertion of chest tube. Drainage catheter is inserted in the right pleural cavity and most of the right lung is reexpanded. There is no definite re-expansion pulmonary edema and small air density of the pneumomediastinum remains. There is also air-collection in the peritoneal cavity along the lateral aspect of the liver indicating pneumoperitoneum. with only a few cases reported. A spontaneous neonatal pneumothorax presented shortly after birth in $1 \%$ to $2 \%$ of all infants, and $10 \%$ of infants show evidence of meconium aspiration [2]. The pneumothorax is symptomatic in approximately half of these [3]. $2-3 \%$ of all cases of neonatal ventilator care are due to pneumothorax. The incidence of spontaneous pneumothorax in male infants is double that in females [2]. Usually the affected infants have a history of fetal distress requiring resuscitation or a difficult delivery with evidence of meconium, blood or mucus aspiration. There is a high incidence of pneumothorax in infants with neonatal respiratory distress syndrome. Ogata et al. [4] encountered 295 newborn infants with the syndrome and reported that $19 \%$ had a pneumothorax.

The development of a spontaneous neonatal pneumothorax is related to the mechanical problems of expanding the lung for the first time. During the first few breaths of life, the transpulmonary pressures averaged $40 \mathrm{cmH}_{2} \mathrm{O}$ with occasional pressures as high as $100 \mathrm{cmH}_{2} \mathrm{O}$ [5]. At birth, the alveoli usually open in rapid sequence. High transpulmonary pressure may lead to a rupture of the lung if there is a bronchial obstruction from the aspiration of blood, meconium, or mucus. A transpulmonary pressure of $60 \mathrm{cmH}_{2} \mathrm{O}$ can rupture an adult lung [3], whereas a transpulmonary pressure of $45 \mathrm{cmH}_{2} \mathrm{O}$ can rupture a neonatal rabbit lung [6]. Therefore, the tension pneumothorax of this case possibly began with spontaneous pneumothorax. Another possibility is pneumothorax is due to neonatal trauma during the fundal pressure. However, the obstetrician stated that the fundal pressure was not high enough, and there was no specific traumatic event during surgery. The fact that the first auscultation was normal and the decreased breathing sound developed later suggests that the pneumothorax may have developed as a result of assisted ventilation. The first fixation at $10 \mathrm{~cm}$ was performed by checking the depth where one lung ventilation is initiated, and manual AMBU bagging was performed by personnel experienced in many cases of neonatal anesthesia. Therefore, the possibility of developing pneumothorax by one lung ventilation and excessively high pressure of manual bagging may be low. It is possible that the first auscultation missed the reduced breathing sound of the right side due to the transmission of a normal contralateral breathing sound, and the second auscultation revealed the

Table 2. Vital Signs during Resuscitation

\begin{tabular}{lccccccccc}
\hline & Birth & $5 \mathrm{~min}^{*}$ & $15 \mathrm{~min}^{\dagger}$ & $30 \mathrm{~min}$ & $35 \min ^{\ddagger}$ & $45 \min ^{\S}$ & $60 \min$ & $75 \mathrm{~min}^{\|}$ & $90 \mathrm{~min}^{\prime \prime}$ \\
\hline $\mathrm{BP}(\mathrm{S} / \mathrm{D})$ & - & - & - & - & $80 / 60$ & $76 / 55$ & $70 / 50$ & $80 / 62$ & $78 / 57$ \\
$\mathrm{HR}(/ \mathrm{min})$ & 58 & 101 & 110 & 122 & 131 & 144 & 145 & 144 & 142 \\
$\mathrm{SpO}_{2}(\%)$ & 59 & 60 & 61 & 64 & 85 & 94 & 96 & 96 & 96 \\
\hline
\end{tabular}

BP: blood pressure, HR: heart rate. *After the administration of epinephrine through an endotracheal tube. ${ }^{\dagger}$ After starting continuous infusion of epinephrine and dopamine through the femoral vein. ${ }^{\ddagger}$ After needle thoracostomy and arterial cannulation. ${ }^{\S}$ After chest tube insertion. "After bolus injection of epinephrine, atropine. 
pneumothorax clearly as the pneumothorax expanded.

To diagnose a pneumothorax, a careful examination of the thorax is important. Normally, the chest is expanded and the motion related to respiration becomes smaller. The breathing sound is reduced but it is difficult to appreciate because the breathing sound of a normal lung may be transmitted easily to the lesion side in the small neonatal thorax [7]. Chernick and Avery [3] said the most reliable sign of tension pneumothorax is a shift in the apical heart impulse away from the side of the pneumothorax. Kuhns et al. [8] reported that transillumination of the neonatal chest using a small, high intensity, cold light can assist in a diagnosis of pneumothorax or pneumomediastinum. Pfenninger et al. [9] reported that pneumopericardium or pneumomediastinum can develop with a pneumothorax, which are difficult to control with a chest tube. A small air density remained in the mediastinum in this case, which might have contributed to the poor prognosis of the neonate.

The initial treatment of neonatal tension pneumothorax is a needle thoracentesis with a 22 gauge blunt cannula in the 2nd intercostal space on the mid-clavicular line converting the tension pneumothorax to an open pneumothorax. Fixing the needle at the skin with hemostatic forceps can avoid lung injury by preventing needle from entering too deeply. Air is gently aspirated with a syringe from the intrapleural space over a few seconds to help re-expand the lung. Tube thoracostomy follows needle thoracentesis and is connected to underwater drainage [9]. However, a surgical approach should be considered if the pneumothorax cannot be resolved with these procedures [10].

Epinephrine should be administered for an asystole or a spontaneous heart rate $<60$ beats/min despite the adequate ventilation and chest compression. Epinephrine may be given in $1 \mathrm{ml}$ of saline down the endotracheal tube if venous access is unavailable. Dopamine or isoproterenol may be infused with the smallest volume to prevent hypervolemia [11].

There are several case reports of neonatal tension pneumothorax. However, these reports are all after day 1 of life. There are no reports of tension pneumothorax that developed immediately after delivery. García Vicente et al. [12] reported a case of a 35-week-old male preterm baby who developed a tension pneumothorax on the second day of birth. A 16 guage intraveous cannula was inserted into the pleural space and was connected to an adult Heimlich valve through a 3-way stopcock, which resolved the tension pneumothorax effectively. Cools et al. [13] reported the unsuccessful resuscitation of a preterm infant due to a pneumothorax and a masked tension pneumopericardium. They recommended that a tension pneumopericardium should be considered if the patient does not recover after pleural drainage and cardiac resuscitation. Mordue [14] reported a case of neonatal pneumopericardium, and concluded that pneumopericardium should be suspected in any infant showing acute deterioration, particularly in the presence of normal, equal breath sounds and muffled heart sounds.

There are also several cases of tension pneumothorax that developed during the induction of anesthesia. Kumar and Walker [7] reported a case of an 8-day-old infant caused by airway trauma from the use of a intubation bougie during induction for the resection of a posterior urethral valve. Iannoli and Litman [15] reported a case due to bronchial trauma associated with the use of a flexible fiberoptic bronchoscope during induction for the repair of esophageal atresia and tracheoesophageal fisula. Needle thoracentesis using an 18 guage intravenous catheter and tube thoracostomy effectively released the air.

In conclusion, tension pneumothorax can develop immediately after the delivery of a neonate. Anesthesiologists should have knowledge of neonatal resuscitation and be prepared for emergencies immediately after delivery. If the neonate is not improved with prolonged resuscitation, tension pneumothorax must be suspected and diagnosed early to improve survival.

\section{References}

1. Wiswell TE. Neonatal resuscitation. Respir Care 2003; 48: 288-94.

2. Gregory GA, Gooding CA, Phibbs RH, Tooley WH. Meconium aspiration in infants: a prospective study. J Pediatr 1974; 85: 848-52.

3. Chernick V, Avery ME. Spontaneous alveolar rupture at birth. Pediatrics 1963; 32: 816-24.

4. Ogata ES, Gregory GA, Kitterman JA, Phibbs RH, Tooley WH. Pneumothorax in the respiratory distress syndrome: incidence and effect on vital signs, blood gases, and pH. Pediatrics 1976; 58: 17783.

5. Karlberg P, Cherry RB, Escardó FE, Koch G. Respiratory studies in newborn infants. II. Pulmonary ventilation and mechanics of breathing in the first minutes of life, including the onset of respiration. Acta Paediatr 1962; 51: 121-36.

6. Adler SM, Wyszogrodski I. Pneumothorax as a function of gestational age: clinical and experimental studies. J Pediatr 1975; 87: 771-5.

7. Kumar S, Walker R. Bougie-related tension pneumothorax in a neonate. Paediatr Anaesth 2009; 19: 800-1.

8. Kuhns LR, Bednarek FJ, Wyman ML, Roloff DW, Borer RC. Diagnosis of pneumothorax or pneumomediastinum in the neonate by transillumination. Pediatrics 1975; 56: 355-60.

9. Pfenninger J, Bossi E, Biesold J, Blumberg A. Treatment of pneumothorax, pneumopericardium and pneumomediastinum. Helv Paediatr Acta 1982; 37: 353-60.

10. Martínez Ibáñez V, Fina A, Salcedo S, Sanchís L, Marhuenda C, Jiménez AI, et al. Surgical approach in persistent neonatal pneumothorax. Cir Pediatr 1989; 2: 76-8.

11. Burchfield DJ, Berkowitz ID, Berg RA, Goldberg RN. Medications in neonatal resuscitation. Ann Emerg Med 1993; 22(2 Pt 2): 435-9.

12. García Vicente E, Tena Espeleta F, López Gimeno O, Medina Santaolalla P, Poudereux de Andrés A, Gobernado Serrano MM. 
Resolved tension pneumothorax in a newborn with an adult Heimlich valve. Resuscitation 2008; 77: 294-5.

13. Cools B, Plaskie K, Van de Vijver K, Suys B. Unsuccessful resuscitation of a preterm infant due to a pneumothorax and a masked tension pneumopericardium. Resuscitation 2008; 78: 236-9.
14. Mordue BC. A case report of the transport of an infant with a tension pneumopericardium. Adv Neonatal Care 2005; 5: 190-200.

15. Iannoli ED, Litman RS. Tension pneumothorax during flexible fiberoptic bronchoscopy in a newborn. Anesth Analg 2002; 94: 512-3. 